\title{
Ecosystem Services Assessment, Trade-Off, and Bundles in the Yellow River Basin, China
}

\author{
Jie Yang ${ }^{1, *}$, Baopeng $\mathrm{Xie}^{2}$, Wenqian Tao ${ }^{2}$ and Degang Zhang ${ }^{1}$ \\ 1 School of Pratacultural Science, Gansu Agricultural University, Lanzhou 730070, China; \\ zhangdg@gsau.edu.cn \\ 2 School of Management, Gansu Agricultural University, Lanzhou 730070, China; xiebp@gsau.edu.cn (B.X.); \\ 13893658916@163.com (W.T.) \\ * Correspondence: 18293893322@163.com
}

check for updates

Citation: Yang, J.; Xie, B.; Tao, W.; Zhang, D. Ecosystem Services Assessment, Trade-Off, and Bundles in the Yellow River Basin, China. Diversity 2021, 13, 308. https:/ / doi.org/10.3390/d13070308

Academic Editors: Michael Wink and Raúl Romero-Calcerrada

Received: 3 June 2021

Accepted: 4 July 2021

Published: 8 July 2021

Publisher's Note: MDPI stays neutral with regard to jurisdictional claims in published maps and institutional affiliations.

Copyright: (C) 2021 by the authors. Licensee MDPI, Basel, Switzerland. This article is an open access article distributed under the terms and conditions of the Creative Commons Attribution (CC BY) license (https:// creativecommons.org/licenses/by/ $4.0 /)$.

\begin{abstract}
Understanding ecosystem services(ESs)and their interactions will help to formulate effective and sustainable land use management plans, and clarifying the balance and synergy between watershed ecosystem services can provide a basis for the regulation of the ecological environment in different regions of the watershed and the maximization of overall ecological benefits. This paper takes the Yellow River Basin as the research object and uses the Ecosystem Services and Trade Offs (InVEST)model to evaluate the water yield (WY), soil conservation (SC), carbon storage (CS) and habitat quality (HQ) of the Yellow River Basin. The paper adopts the Carnegie-Ames-Stanford Approach (CASA)model to evaluate the net primary productivity (NPP), draws the spatial distribution map of the five ecosystems, analyzes the trade-off and synergy between the five ecosystems using correlation and binary spatial correlation, and expresses it in space. In addition, it adopts self-organizing mapping (SOM) method to identify ecosystem service clusters. The results show that: (1) ES is generally higher in the upper reaches of the Yellow River, and lower in the middle reaches. (2) WY and NPP, HQ, CS and WY are trade-off relationships, and other ecosystem services are synergistic relationships. Trade-offs and synergy show obvious spatial heterogeneity. (3) The ecosystem services of the Yellow River Basin, driven by different factors, can be divided into three areas, namely WY and SC service leading functional areas, HQ and CS service leading functional areas, and NPP service leading functional areas. Finally, it discusses the driving factors of the spatial heterogeneity of the balance of the ecosystem service functions of the Yellow River Basin and the suggestions of land use management in the basin.
\end{abstract}

Keywords: ecosystem service bundles; spatial distribution characteristics; relatedness; Yellow River Basin

\section{Introduction}

Ecosystems provide a wide range of valuable goods and services that contribute to ward supporting nature [1]; these are the material bases and environmental conditions for the survival and development of humans, and can be divided into three categories: supply services, regulation services, and social and cultural services. They are the bridges to connect natural ecosystems and human well-being [2]. Sustainable supply is of great significance, in regards to the sustainable development of districts, countries, and the whole world [3]. Many ecosystems including forests across the globe, are degrading, despite significant conservation efforts [4]. ESs have gradually received attention in sustainable development research, and their definitions, classifications, evaluations, and driving mechanisms have been extensively studied [5]. The research focus has gradually shifted from the structure and process of ecosystems to the relationship between human activities and ESs [6]. Changes in environmental factors, such as land-use change and climate change will affect multiple ecological processes, such as the water cycle and carbon cycle, causing simultaneous changes in different ESs, and different services may be related to the same 
ecological process, which ultimately leads to complex connections between different ESs [7]. The connections can be divided into three categories: trade-off, synergy, and irrelevance. The trade-off relationship indicates that the improvement of one service is accompanied by the decrease of another service; synergy indicates that two services are increased or decreased at the same time, while irrelevance indicates no significant connections between the temporal and spatial changes of the two services [8]. The trade-off relationship analysis is of great significance in the management and policy-making of ESs. It has gradually attracted the attention of researchers, becoming a hot research topic in related fields.

In recent years, trade-off and synergy of ES research has proliferated at an exponential rate. Mouchet et al. reviewed and analyzed the main methods of exploring trade-off relationships quantitatively in existing research [9]. Deng, et al. summarized the main tools and processes applied in the analysis of trade-off relationships in land use management research [10]. Howe, et al. conducted a comprehensive analysis of how social-ecological environmental factors cause the trade-off relationship between services [11]. Richards et al. explored the trade-off relationship between ESs in tropical coastal areas and future urban development, using the Pareto curve to analyze the trade-off and synergy relationship between habitat quality and various ecological indicators [12]. Trodahl et al. studied the trade-off and synergy relationship between the water quality and agricultural productivity of the fertile bay of New Zealand based on the LUCI module [13]. Tolessa et al. studied the impact of land use and land cover changes on ESs in the central highlands of Ethiopia from 1973 to 2015, and the results showed that the reduction of forest coverage will lead to a decrease in the value of ESs, which is mainly manifested in the ESs such as nutrient circulation, raw material supply, and erosion control [14]. Sun et al. used Yan'an City as the research area, applied partial correlation analysis and found that there is a trade-off relationship among food supply and soil conservation, water conservation and NPP, and there is a synergistic relationship between NPP and soil conservation and water conservation, there is a synergistic relationship between soil conservation and water conservation [15]. Fu et al. studied ES trade-offs and regional integration methods and analyzed the relationship between land use change and ESs [16]. Taking the Shiyang River Basin as an example, Wang Bei et al. used the InVEST model and correlation coefficient method to study the trade-offs and synergies relationships among five services, including water conservation, soil conservation, water purification, carbon storage, and biodiversity [17]. Many studies have achieved some achievements in the trade-offs and synergy of ESs, but the research on the regional differences, and the driving factors in the trade-offs and synergy relationship of ESs are still very inefficient. For example, the existing studies mostly analyze natural environmental factors, such as terrain and climate [18], ignoring the influence of social and economic development conditions [19], even lacking comparative studies on the relative influence of different social ecological factors [20], and lacking comprehensive analysis of driving forces and the identification of dominant driving forces, consequently limiting the application of research on ES relationships in management practices.

Watershed is the best geographical unit for studying ecosystem services [21]. It has a variety of service types. Under the combined effect of social and ecological factors, ESs exhibit complex temporal and spatial relationships. The Yellow River Basin is an important ecological barrier in China. It is an ecological corridor connecting the Qinghai-Tibet Plateau, the Loess Plateau and the North China Plain. The Yellow River Basin has ecological functions such as water conservation, wind prevention and sand fixation, and biodiversity protection, which play a very important role in maintaining regional ecological security. The basin has the characteristics of complex geomorphic unit, diversified ecosystem types, and obvious regional climate differences. The ecosystem environment is fragile, and it is one of the regions which have sensitive climate change in the global [22], and it is also one of the regions most disturbed by human activities. With the intensification of human activities and climate change, the basin faces many problems, such as insufficient water supply, soil erosion, and degradation of habitat quality. How to coordinate the 
relationship between economic development and environmental protection, and alleviate the conflicts between upstream and downstream stakeholders, has become, the key to the sustainable development of the basin, which requires managers to clarify the various ecosystem services and their relationships firstly. As the Yellow River Basin spans multiple climate zones, there are significant differences in precipitation and evaporation, resulting in different patterns of water production in the upper and lower reaches of the basin, which profoundly affect the spatial pattern of the basin's ecosystem. The Loess Plateau is the largest loess region in the world. The loose soil, high rainfall intensity, and large slope have caused serious soil erosion, seriously affecting the ecological security of the downstream seriously. In recent years, the rapid speed of urbanization and economic development of the downstream areas have led to a rapid decline in biodiversity. In addition, the Yellow River Basin has a large amount of grasslands and woodlands; it is an important carbon sink area. It is considered a typical representative area of a fragile ecological environment. Studying the temporal and spatial characteristics of the trade-off and synergistic relationships among multiple ecosystem services in the Yellow River Basin, could provide a reference for regional ecological restoration and management, a scientific basis for ecological compensation and biodiversity protection in the upper, middle and lower reaches of the region. Based on this, this study uses 2018 as a cross-section to analyze the spatial trade-offs among the five ecosystem services and their associations with social ecosystems.It quantitatively calculates the spatial distribution pattern of water production (WY), carbon storage (CS), soil conservation (SC), habitat quality (HQ), and NPP;calculates the correlation coefficient between ESs through correlation analysis, and adopts the SOM method to divide social ecological factor clustering. Ffinally, it identifies the relationship between the ecosystem service clustering and the social ecological factor clustering through the overlay analysis, and explores the response mechanism of ecosystem services to the social-ecological system. It is expected to lay the foundation for the ecological and environmental protection of the basin. The framework of the methodological process is shown in Figure 1.

\section{Research objectives}

Assess the five typical ecosystem services and their spatial pattern characteristics quantitatively

- Calculate the correlation coefficient between the ESs

- Classify the spatial distribution of ES clusters

\section{Research process}

Water yield (WY)

Carbon storage (CS)

Soil conservation (SC)

Habitat quality (HQ)

Net primary productivity of plants (NPP)

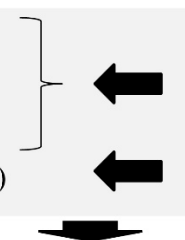

The Model of Integrated Valuation of Ecosystem Services and Trade-offs (InVEST)

The Model of Carnegie-Ames-Stanford approach (CASA)

ESs and their spatial distribution characteristics

Arcmap 10.2 was used for spatial statistics and analysis

\section{Trade-Off and synergy of ESs}

Global scope:through correlation analysis

In terms of space:through bivariate spatial autocorrelation

Identify the Yellow River Basin ES bundles by using the SOM model

1. Divide the five ESs into three clusters based on the results of principal component analysis

2. On the basis of the ecological function bundles, it obtains the ESs of each ecological function in the district and performs normalization processing by adopting the district statistics

Figure 1. The framework of the methodological process. 


\section{Study Area}

The Yellow River originates from the Yogu Zonlie Basin at the northern foot of the Bayan Har Mountain on the Qinghai-Tibet Plateau. It flows through Qinghai, Sichuan, Gansu, Ningxia, Inner Mongolia, Shanxi, Shaanxi, Henan, and Shandong provinces, and injects into the Bohai Sea in Kenli County, Shandong Province. The main stream has a total length of $5464 \mathrm{~km}$ and a drop of $4480 \mathrm{~m}$ (Figure 2). The Yellow River Basin is located between $96^{\circ}$ and $119^{\circ}$ east longitude and $32^{\circ}$ and $42^{\circ}$ north latitude, with a length of about $1900 \mathrm{~km}$ from the east to the west, and a width of about $1100 \mathrm{~km}$ from the north to the south. The area of the basin is 795,000 square kilometers (including the internal flow area of 42,000 square kilometers). Above Hekou Town, it is the upper reaches of the Yellow River, with a river course of $3472 \mathrm{~km}$ and a basin area of 428,000 square kilometers. From Hekou Town to Taohuayu, it is the middle reaches, with a river course of $1206 \mathrm{~km}$ and a basin area of 344,000 square kilometers. Below Taohuayu, it is the lower reaches, with a river course of $786 \mathrm{~km}$ and a basin area of only 23,000 square kilometers. In the Yellow River Basin, there is a vast area, numerous mountains, great differences in height between the east and the west, and great differences in landforms between regions. The climate of different regions in the basin differs significantly. In the Yellow River Basin, the sunlight is sufficient and the solar radiation is strong, and the sunshine conditions belong to sufficient areas across the country. The annual hours of sunshine generally reach 2000-3300. There are big seasonal differences in the Yellow River Basin. The annual precipitation in most areas of the basin is between 200 and $650 \mathrm{~mm}$, and that of the upper reaches of the southern and lower reaches is more than $650 \mathrm{~mm}$, especially the northern slope of the Qinling Mountains in the south, which is heavily affected by topography. Generally, it can reach $700-1000 \mathrm{~mm}$, and it gradually increases from the northwest to the southeast. The precipitation is unevenly distributed, and the ratio of rainfall between the north and the south is greater than 5. According to the national water resources distribution, the Yellow River basin can be divided into eight secondary basins and 29 tertiary basins.

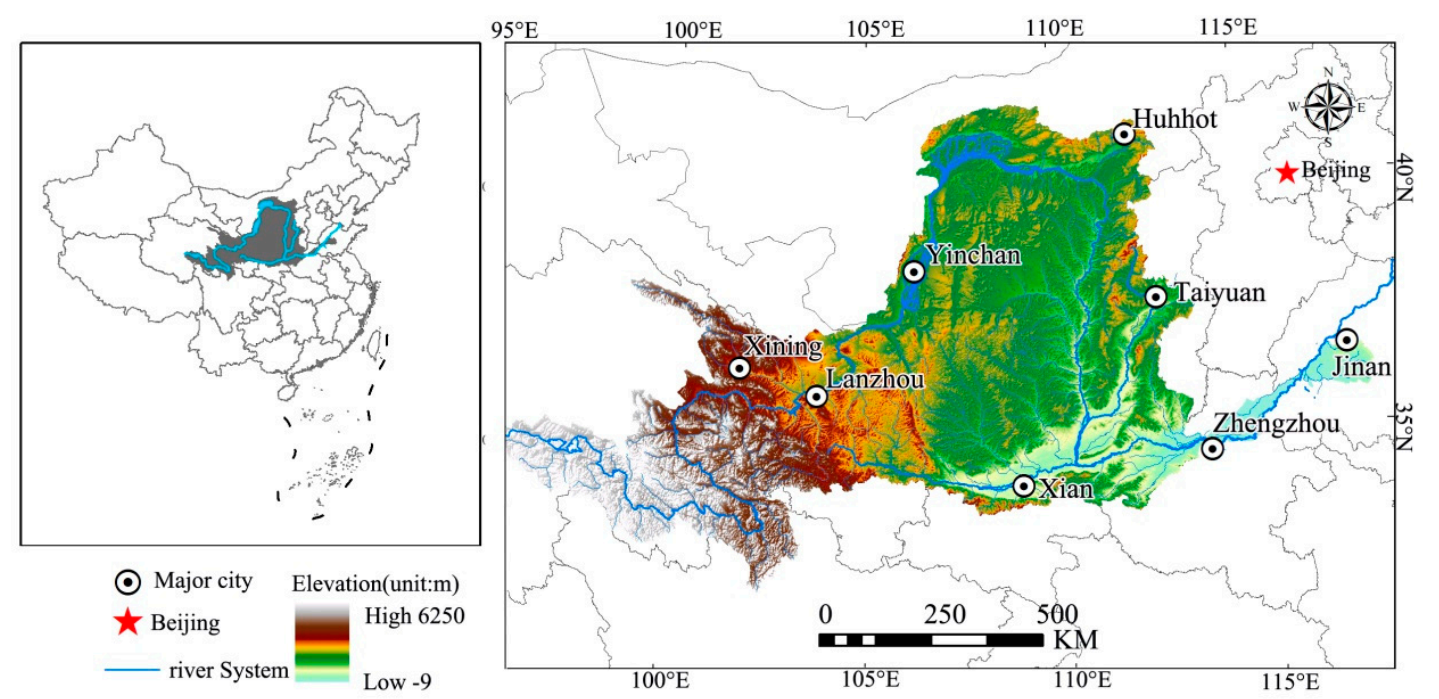

Figure 2. Range of the Yellow River Basin and distribution of the river system.

\section{Data and Methodology}

\subsection{Data Sources}

In this study, we use multi-source data sets to evaluate ESs in space, including land use/cover data sets, satellite image data sets, meteorological data sets, soil data sets, statistical data sets and related auxiliary data sets. Detailed descriptions of data sources are shown in Table 1. 
Table 1. Summary of main data types and data sources.

\begin{tabular}{|c|c|c|c|}
\hline ES & Data Requirement Type & Unit & Data Sources \\
\hline \multirow{8}{*}{ WY } & Precipitation & $\mathrm{mm}$ & $\begin{array}{c}\text { Geographic Data Cloud of Chinese Academy of } \\
\text { Sciences }\end{array}$ \\
\hline & Potential evapotranspiration & $\mathrm{mm}$ & $\begin{array}{l}\text { The Data Set of Global Potential } \\
\text { Evapotranspiration and Global Drought Index }\end{array}$ \\
\hline & Soil texture & int & HWSD Soil Database \\
\hline & Available water content of plant & $\%$ & Generated from soil texture data \\
\hline & Land use/cover type & int & $\begin{array}{c}\text { Geographical national conditions monitoring } \\
\text { cloud platform }\end{array}$ \\
\hline & $\begin{array}{l}\text { Catchment area/sub-catchment area } \\
\text { distribution }\end{array}$ & int & DEM data generation \\
\hline & Root depth of plant & $\mathrm{mm}$ & 1:1 million soil database of China \\
\hline & Evapotranspiration coefficient & - & $\begin{array}{l}\text { Food and Agriculture Organization of the } \\
\text { United Nations, } 1998\end{array}$ \\
\hline \multirow{2}{*}{ CS } & Land use / cover type & int & $\begin{array}{l}\text { Geographical national conditions monitoring } \\
\text { cloud platform }\end{array}$ \\
\hline & $\begin{array}{c}\text { Carbon density data of various land } \\
\text { use types }\end{array}$ & $\mathrm{t} / \mathrm{hm}^{2}$ & InVEST model, references \\
\hline \multirow{7}{*}{ SC } & DEM & $\mathrm{m}$ & Geospatial Data Cloud \\
\hline & Rainfall erosivity & $\mathrm{MJ} \cdot \mathrm{mm} /\left(\mathrm{hm}^{2} \cdot \mathrm{h} \cdot \mathrm{a}\right)$ & Calculation based on rainfall data \\
\hline & Soil erodibility factor & $\mathrm{t} \cdot \mathrm{hm}^{2} /(\mathrm{MJ} \cdot \mathrm{mm})$ & Calculation based on soil texture data \\
\hline & Land use / cover type & int & $\begin{array}{l}\text { Geographical national conditions monitoring } \\
\text { cloud platform }\end{array}$ \\
\hline & $\begin{array}{l}\text { Catchment area/sub-catchment area } \\
\text { distribution map }\end{array}$ & int & DEM data generation \\
\hline & Vegetation Management Factor & - & Calculation based on NDVI data \\
\hline & Engineering measures factor & - & references \\
\hline \multirow{4}{*}{ HQ } & Land use/ cover type & int & $\begin{array}{l}\text { Geographical national conditions monitoring } \\
\text { cloud platform }\end{array}$ \\
\hline & Major threats & - & InVEST model, references \\
\hline & The weight of threat source factor & - & InVEST model, references \\
\hline & $\begin{array}{l}\text { Sensitivity of various land use types } \\
\text { to stress factors }\end{array}$ & - & InVEST model, references \\
\hline \multirow{3}{*}{ NPP } & Land use / cover type & int & $\begin{array}{c}\text { Geographical national conditions monitoring } \\
\text { cloud platform }\end{array}$ \\
\hline & NDVI & int & Earth resources observation and science center \\
\hline & Meteorological data & int & $\begin{array}{c}\text { Geographical national conditions monitoring } \\
\text { cloud platform }\end{array}$ \\
\hline
\end{tabular}

\subsection{ES Quantification and Mapping}

This study selects water yield (WY), soil conservation (SC), carbon storage (CS), habitat quality (HQ), and vegetation net primary productivity (NPP), etc., which are the five more important ecosystem services in the ecosystem services, considering that the Yellow River Basin is facing prominent ecological problems such as vegetation degradation, insufficient water supply, soil erosion, and degradation of habitat quality, and it is an important carbon sink area in China. Among them, WY, SC, CS, and HQ of the Yellow River Basin are evaluated by using the InVEST model, which has been widely used in the evaluation of ecosystem service functions due to its few model parameters, low data requirements, and global universality. NPP in the Yellow River basin adopts the CACA model ENVI remote sensing estimation module for evaluation. This method has simplified parameters and takes the impact of vegetation classification on the evaluation results into account, which is due to the availability of the model parameters; the simplicity of operation has been widely applied to the estimation of NPP. 


\subsubsection{Net Primary Productivity (NPP)}

The calculation formula of this method is:

$$
\begin{gathered}
\mathrm{NPP}=\mathrm{APAR} \times \varepsilon \\
\mathrm{APAR}=\mathrm{SOL} \times \mathrm{FPAR} \times 0.5 \\
\mathrm{FPAR}=\min \left[\frac{S R-S R_{\text {min }}}{S R_{\text {max }}-S R_{\text {min }}}, 0.95\right] \\
\mathrm{SR}=\left[\frac{1+\mathrm{NDVI}}{1-\mathrm{NDVI}}\right] \\
\varepsilon=T_{\varepsilon 1} \times T_{\varepsilon 2} \times W_{\varepsilon} \times \varepsilon_{\text {max }}
\end{gathered}
$$

In the formula, NPP, APAP, $\varepsilon$ respectively represent the net primary productivity of vegetation $\left(\mathrm{gc} \cdot \mathrm{m}^{-2}\right)$, the absorbed photosynthetically active radiation $\left(\mathrm{MJ} \cdot \mathrm{m}^{-2}\right)$ and the actual light utilization rate $\left(\mathrm{g} \mathrm{c}_{\mathrm{C}} \mathrm{MJ}^{-1}\right)$. SOL and FPAR are respectively the total solar radiation $\left(\mathrm{MJ} \cdot \mathrm{m}^{-2}\right)$ and the absorption ratio of photosynthetically active radiation by vegetation; the constant 0.5 represents the solar radiation rate used by vegetation; $S R_{\min }$ is 1.08 , and $S R_{\max }$ is related to vegetation types. NDVI represents vegetation coverage; $T_{\varepsilon 1}, T_{\varepsilon 2}$ and $W_{\varepsilon}$ are the threat effects of low temperature, high temperature, and moisture conditions on the light utilization efficiency. For specific algorithms, please refer to Piao et al. [23], Zhu et al. [24,25] and Mu et al. [26].

\subsubsection{Water Yield (WY)}

This study evaluates the water yield by adopting the InVEST model water production module, which is based on the Budyko water-heat coupling balance hypothesis and the annual average precipitation data, that is, the rainfall of each grid minus the actual evapotranspiration is the annual water production $Y(x)$ of each grid unit $x$ in the study area [27], the calculation formula is:

$$
\begin{gathered}
Y_{x j}=\left(1-\frac{A E T_{x}}{P_{x}}\right) \times P_{x} \\
\frac{A E T_{x}}{P_{x}}=\frac{1+w_{x} R_{x}}{1+w_{x} R_{x j}+\frac{1}{R_{x}}} \\
w_{x}=\mathrm{Z} \times\left(\frac{A W C_{x}}{P_{x}}\right) \\
R_{x}=\frac{k_{x} \times E T_{o x}}{P_{x}} \\
A W C_{x}=\operatorname{Min}\left(M S D_{x}, R D_{x}\right) \times P A W C_{x}
\end{gathered}
$$

In the formula, $Y_{x}$ is the average annual water production of grid $x$. Since the actual annual evapotranspiration cannot be directly measured and obtained, the curve pair $A E T_{x} / P_{x}$ can be used to approximate calculations. The $R_{x}$ value is dimensionless and is the dryness index of grid $x$. It can be calculated by potential evapotranspiration and rainfall. $w_{x}$ is an empirical parameter used to describe climate soil properties, and can be calculated by the available water content of vegetation and annual rainfall. $A W C_{x}$ is the available water content of vegetation, which is determined by soil texture and effective soil depth and is used to determine the total amount of water stored and provided by the soil for plant growth. $Z$ is called the Zhang coefficient [28], which is an empirical constant, which represents the parameters of seasonal rainfall distribution and rainfall depth. For areas dominated by winter rainfall, the $Z$ value is close to 10 , while for humid areas where rainfall is evenly distributed and areas dominated by summer rainfall, the $Z$ value is close to 1 . According to the results of multiple simulations, the $Z$ value is finally determined to be 3.6. $E T_{0 x}$ is the internal potential evapotranspiration in grid $x$, which reflects the evapotranspiration capacity determined by weather and climate conditions. Since the data 
of potential evapotranspiration are difficult to obtain, they are usually calculated by the temperature method, the radiation method and the comprehensive method. The InVEST model uses the modified -Hargreaves method to calculate the potential evapotranspiration. $k_{x}$ represents the evapotranspiration coefficient of vegetation or crops, and there are different evapotranspiration coefficients for different land use types. $M S D_{x}$ (Max Soil Depthx) is the maximum soil depth. $R D_{x}$ is the root depth. PAWC is the available moisture content of plants. Please refer to Yang et al. for the calculation of specific parameters [29].

\subsubsection{Carbon Storage (CS)}

This paper divides the carbon storage of the ecosystem into four basic carbon pools by using the InVEST model carbon storage module. They are respectively: the above-ground biological carbon (carbon in all living plant materials above the soil), the underground biological carbon (carbon presents in the living root system of plants), the soil carbon (organic carbon distributed in organic soil and mineral soil), and the dead organic carbon (carbon in litter, upside-down or standing dead trees). The carbon module of the model takes each land use type as the evaluation unit and multiplies the average density of the four carbon pools by the area of each evaluation unit to calculate the carbon storage of the study area. The calculation formula for the total carbon density of each land-use type is as follows:

$$
\mathrm{C}_{\text {tot }}=\mathrm{C}_{\text {above }}+\mathrm{C}_{\text {below }}+\mathrm{C}_{\text {soil }}+\mathrm{C}_{\text {dead }}
$$

In the formula: $\mathrm{C}_{\text {tot }}$ is the total carbon storage $\left(\mathrm{t} \cdot \mathrm{hm}^{-2}\right) . \mathrm{C}_{\mathrm{above}}, \mathrm{C}_{\text {below }}, \mathrm{C}_{\text {soil }}, \mathrm{C}_{\text {dead }}$ are the above-ground biological carbon storage $\left(\mathrm{t} \cdot \mathrm{hm}^{-2}\right)$, the underground biological carbon storage $\left(\mathrm{t} \cdot \mathrm{hm}^{-2}\right)$, the soil carbon storage $\left(\mathrm{t} \cdot \mathrm{hm}^{-2}\right)$, and the dead organic carbon storage $\left(\mathrm{t} \cdot \mathrm{hm}^{-2}\right)$.

Based on the carbon density and land use data of various regions, the formula for calculating the carbon storage of the ecosystem in the basin is as follows:

$$
C_{t o t i}=\left(C_{a i}+C_{b i}+C_{s i}+C_{d i}\right) \times A_{i}
$$

In the formula: $i$ is the average carbon density of each land use type. $A_{i}$ is the area of the land-use type. Please mainly refer to related studies [30-33] for the carbon density data in the carbon pool table required for the model. According to regional similarity, the desirability of results, and other principles, it can generate a carbon pool table.

\subsubsection{Soil Conservation (SC)}

In this paper, the amount of soil conservation includes two parts: the amount of erosion reduction and the amount of sediment interception based on the calculating principle of the soil conservation module in the InVEST model. The former refers to the reduction of potential erosion land of each block, expressed as the potential erosion and actual erosion difference. The latter refers to the retention of sediment from the upslope by the block, which is expressed as the product of the amount of sediment and the efficiency of sediment retention. The model calculation formulas are as follows:

$$
\begin{gathered}
S E D R E T_{x}=R K L S_{x}-U S L E_{x}+S E D R_{x} \\
R K L S_{x}=R_{x} \times K_{x} \times L S_{x} \\
U S L E_{x}=R_{x} \times K_{x} \times L S_{x} \times P_{x} \times C_{x} \\
S E D R_{x}=S E_{x} \sum_{y=1}^{x-1} U S L E_{y} \prod_{z=y+1}^{x-1}\left(1-S E_{z}\right)
\end{gathered}
$$

In the formula: SEDRET $x, R K L S_{x}, U S L E x, S E D R x$ and USLEy are respectively the soil conservation amount of grid $x$, the potential soil erosion amount, the actual erosion amount after considering management and engineering measures, the sediment retention amount, and the actual erosion amount of the upslope grid $y$ after considering management and 
engineering measures, which are all in units of $\mathrm{t}$. Moreover, $R_{x}, K_{x}, L S_{x}, C_{x}$, and $P_{\mathrm{x}}$ are the precipitation erodibility factor, soil erodibility factor, slope length factor, vegetation cover management factor, and soil and water conservation measures factor of grid $x$, respectively. Please refer to Liu et al. for the calculation process of each factor [34].

\subsubsection{Habitat Quality (HQ)}

In the InVEST model, the Habitat Quality model evaluates the quality of the habitat. The model calculates the negative impact of threatening factors on the habitat, and obtains the degradation degree of the habitat, by establishing the connection between land use data and threat factors, and comprehensively considering factors such as the distance and intensity of threat factors. Then it calculates the quality of the habitat through the degradation degree and habitat suitability to reflect the biodiversity of the area [35]. The calculation formula is:

$$
Q_{x j}=H_{j}\left(1-\left(\frac{D_{x j}^{z}}{D_{x j}^{z}+k^{z}}\right)\right)
$$

In the formula: $Q_{x j}$ is equal to the habitat quality index of grid $x$ in land use $j . H_{j}$ refers to the habitat suitability of habitat type $j$, with a value range of $0-1$. $D_{x j}$ refers to the habitat degradation index. $R$ is the number of threat factors. $k$ is the half-saturation constant, which is generally $1 / 2$ of the maximum value of habitat degradation. $z$ is the normalized constant, which is usually set to 2.5 [27].

The parameters that need to be input in this module mainly include land-use type maps, main habitat threat factors, weights of threat source factor and influence distances, and data such as the sensitivity degree of land use types to threat sources, etc. These research results are set after taking reference to the InVEST model manual [27], the scholars research results [36-38] and experts' suggestions.

\subsection{Trade-Offs, Synergy, and Bundle Analysis among ESs}

\subsubsection{Correlation Analysis}

Correlation analysis can effectively reflect the direction and degree of the changing trend between two variables [39]. The commonly used correlation coefficients are Pearson coefficient, Spearman coefficient, and Kendall coefficient. The Spearman rank correlation coefficient mainly performs the linear correlation analysis by using the rank size, and it does not require the distribution of the original variables. It is a non-parametric statistic method [40], and has lower requirements on the original data [41]. The overall distribution pattern or sample size is not required. As long as the observation values of the two variables are paired with each other, the coefficient can be used for calculation, and even the grade data converted from continuous variables can be analyzed. The scope of application is very wide [42]

$$
\begin{gathered}
P_{X, Y}=\frac{\operatorname{cov}(X, Y)}{\sigma_{X} \sigma_{Y}}=\frac{E\left(\left(X-\mu_{X}\right)\left(Y-\mu_{Y}\right)\right)}{\sigma_{X} \sigma_{Y}}=\frac{E(X Y)-E(X) E(Y)}{\sqrt{E\left(X^{2}\right)-E^{2}(X)} \sqrt{E\left(Y^{2}\right)-E^{2}(Y)}} \\
r_{g}=P_{r g X, r g Y}=\frac{\operatorname{cov}(r g X, r g Y)}{\sigma_{r g X} \sigma_{r g} Y}
\end{gathered}
$$

In the formula, $P_{X, Y}$ is the Pearson correlation coefficient of variables $X$ and $Y$. $\operatorname{cov}(X, Y)$ is the covariance of the two variables. $\sigma_{X}$ and $\sigma_{Y}$ are the standard deviation of the two variables. $P_{r g X, r g Y}$ is the Spearman correlation coefficient, which is applied to the rank of the original variable.

Based on the correlation analysis function of the $\mathrm{R}$ language, this research explores the trade-offs and synergy relationships among the five ESs of NPP, WY, CS, SC, and HQ The pie chart shows the correlation between the service function of ESs. Blue means positive correlation, red means negative correlation. The darker the color, the greater the correlation between the two variables. The meaning of the color of the upper triangular cell in the figure is the same as that of the lower triangular cell, but the degree of correlation is expressed by the filled area of the graph chart in the pie. The greater the correlation, the 
more the filled area. The positive correlation fills the pie chart clockwise from, and the negative correlation fills the pie chart counterclockwise.

\subsubsection{Global Spatial Autocorrelation}

Moran's I index shows the similarity ratio of unit attribute values in the spatial adjacent areas. In this paper, it analyzed the spatial correlation between water yield and rainfall of each grid cell in the Yellow River Basin by GeoDA. The formulas are in the following:

$$
\begin{gathered}
I=\frac{n \sum_{i=1}^{n} \sum_{j=1}^{n} w_{i j}\left(x_{i}-\bar{x}\right)\left(x_{j}-\bar{x}\right)}{\sum_{i=1}^{n}\left(x_{i}-\bar{x}\right)^{2}\left(\sum_{i} \sum_{j} w_{i j}\right)} \\
Z\left(G_{i}^{*}\right)=\frac{\sum_{j=1}^{n} w_{i, j} x_{j}-X \sum_{j=1}^{n} w_{i, j}}{\sqrt[s]{\frac{\left[n \sum_{j=1}^{n} w_{i, j}^{2}-\left(\sum_{j=1}^{n} w_{i, j}\right)^{2}\right]}{(n-1)}}} \\
X=\frac{1}{n} \sum_{j=1}^{n} x_{i}, S=\sqrt{\frac{1}{n} \sum_{j=1}^{N} x_{j}^{2}-x^{2}}
\end{gathered}
$$

In the formula: I is Moran's $I$ index, $n$ is spatial cells' number; $x_{i}$ and $x_{j}$ are respectively the observed values of $i$ and $j$ regions; $w_{i j}$ is the spatial adjacency relationship of regions $i$ and $j$; S2 is the variance of observed values. The Moran's $I$ index is generally between -1 and $1 .[0,1]$ indicating that the geographical entities have a positive correlation, and $[-1,0]$ shows a negative correlation, and the value of 0 indicates there is no correlation.

\subsubsection{Principal Component Analysis}

Principal Component Analysis (PCA) is a method of mathematical transformation, which converts a given set of related variables into another set of unrelated variables which are arranged in descending order based on variance through linear transformation. In the mathematical transformation, the total variance of the variable is unchanged, so that in the first variable, there is the largest variance called the first principal component, and in the second variable, there is the second-largest variance, and it has no relation with the first variable, which is considered the second principal component. By analogy, one variable has one principal component. The steps are as follows: (1) standardization of multivariate data; (2) determination of correlation between variables; (3) determination of the number of principal components; (4) obtaining of the principal components.

\subsubsection{SOM Method}

The SOM is an unsupervised neural network method based on competitive learning [43]. It is composed of an input layer and an output layer (also called a competition layer). The input layer is used to receive input training samples. The neurons in the output layer are generally arranged in a two-dimensional array, and each neuron in the two layers is bidirectionally connected. The SOM classifies the set of input patterns by finding the optimal weight vector that is, the best matching neuron. The steps of the SOM algorithm are: initializing each weight vector that is, assigning small random numbers to each weight vector in the output layer and normalize it; finding the winning neuron of the input data; adjusting the weight vector in the winning neighborhood; repeatedly searching for the input data of the winning neuron and subsequent steps until the iteration termination condition is met.

\section{Results and Analysis}

\subsection{ESs and Their Spatial Distribution Characteristics}

In 2018, the five ESs of NPP, WY, CS, SC and HQ in the Yellow River Basin were $336.99 \mathrm{gc} \cdot \mathrm{m}^{-2}, 451.695 \times 10^{8} \mathrm{~m}^{3}, 15.4685 \times 10^{6} \mathrm{t}, 78.4265 \times 10^{8} \mathrm{t}$ and 0.684 , respectively. The five ESs functions studied in this study are calculated and displayed on the map. They 
are unevenly distributed (Figure 3). The areas with high NPP values are distributed mainly in the lower reaches of the Yellow River (Figure 3a), including the Weihe-Guanzhong Basin, Fenhe River Basin, as well as the area below Huayuankou. The low-value areas are mainly distributed in the middle reaches of the Yellow River Basin, including the Lanzhou to Hekouzhen watershed, etc., showing a zonal pattern of high in the east and low in the west. WY shows the highest water production in the upper reaches of the Yellow River, such as areas of Longyangxia and above (Figure $3 b$ ). This area has more ice and snow melt water replenishment, higher vegetation coverage, and low evapotranspiration. It is the main source of runoff in the Yellow River Basin, and the main stream has a large runoff. The basin from Lanzhou to Hekou Town is the low-value area of WY. The evaporation in this area is strong, and the precipitation is relatively low. The overall performance of CS is that the upper reaches of the Yellow River Basin (Figure 3c), the Luohe River Basin, the Fenhe River Basin and the Qinling Mountains are high-value areas of CS. The above-mentioned areas have good vegetation conditions and strong carbon sequestration capacity. The low-value areas are mainly distributed in the Loess Plateau, especially the Mu Us sandy area in the north of the Loess Plateau and the Badain Jaran Desert in the north of the Helan Mountain and in the west of the Yellow River. The basins with higher SC are mainly distributed in the upper reaches of the Yellow River Basin and the central area of the Loess Plateau (Figure 3d), especially the upper reaches of the Yellow River, while the SC from Lanzhou to Hekou Town, the Hetao Plain and the lower reaches of the Yellow River are relatively low. The high HQ areas are mainly distributed in the upper river basins and the Taihang Mountains (Figure 3e). The main land cover in this area is woodland and grassland. Human activities are infrequent and the level of biodiversity is high. The lower areas are mainly distributed in the Guanzhong Basin, Weihe Valley and the lower Yellow River plain area. This area is a concentrated distribution area of cultivated land and construction land in the Yellow River Basin, highly disturbed by human activities.

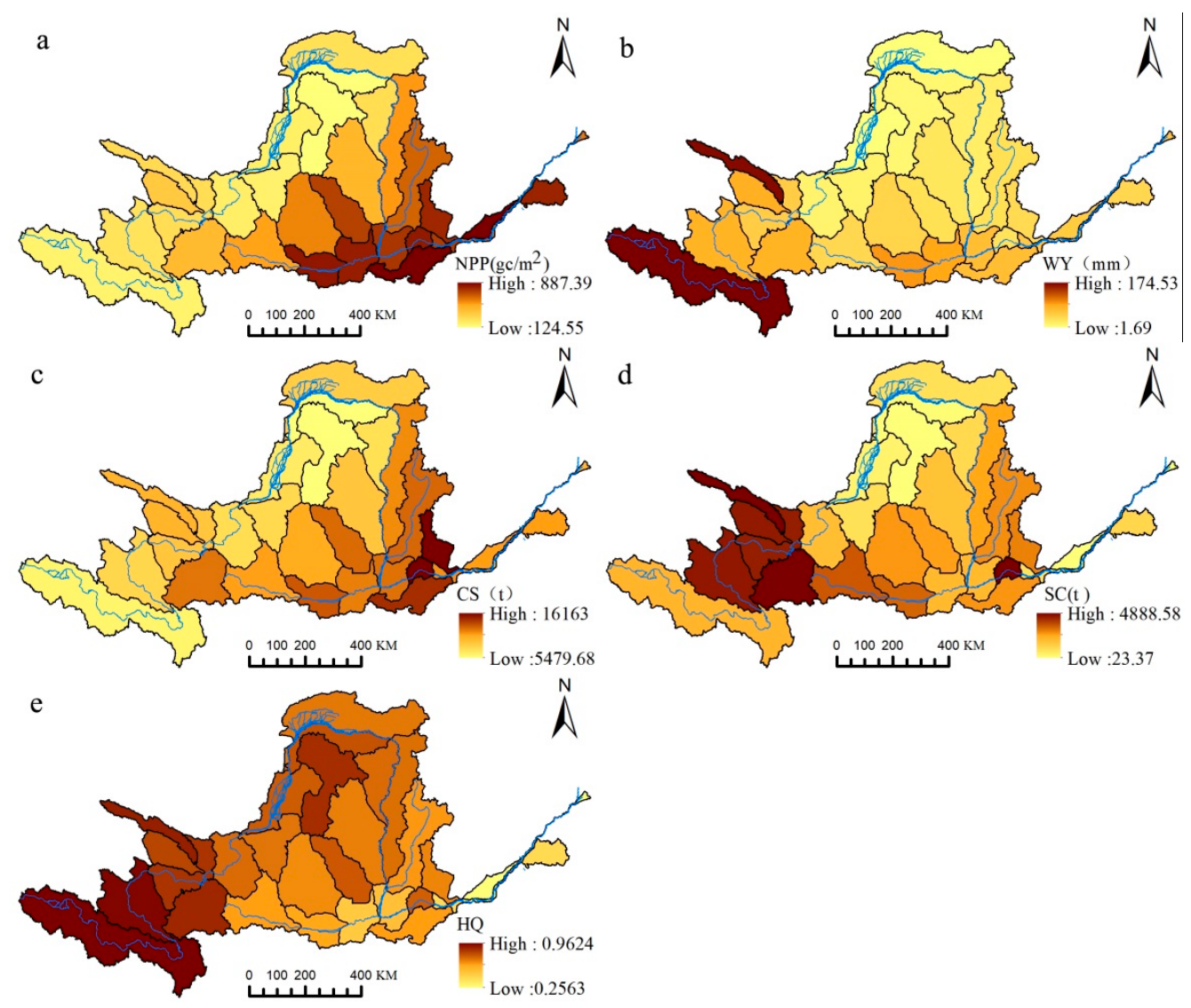

Figure 3. Spatial distribution map of ESs in the Yellow River Basin. (a: NPP; b: WY; c: CS; d: SC; e: HQ). 
From the spatial distribution of the five ESs, some show relatively similar spaces, such as HQ and CS, while others show opposite spatial characteristics, such as WY and CS. In short, the five ESs are agglomerated and related in space, rather than randomly distributed with each other.

\subsection{Trade-Off and Synergy of ESs in the Yellow River Basin}

The correlations between various ESs are shown in the pie chart (Figure 4). Except for the negative correlation between NPP and HQ, and CS and WY, the correlation coefficients are -0.0139 and -0.0179 , respectively, and the other eight combinations are all positively correlated. The positive correlation between NPP and CS is the strongest $(r=0.2515)$, followed by CS and HQ ( $r=0.1907)$. The results show that NPP has a synergistic relationship with CS, SC, and WY, and a trade-off relationship with HQ. There is a synergistic relationship among CS, and SC, and HQ, and a trade-off relationship with WY. The relationships among SC and HQ, SC and WY are all synergistic, as well as the relationship between HQ and WY.

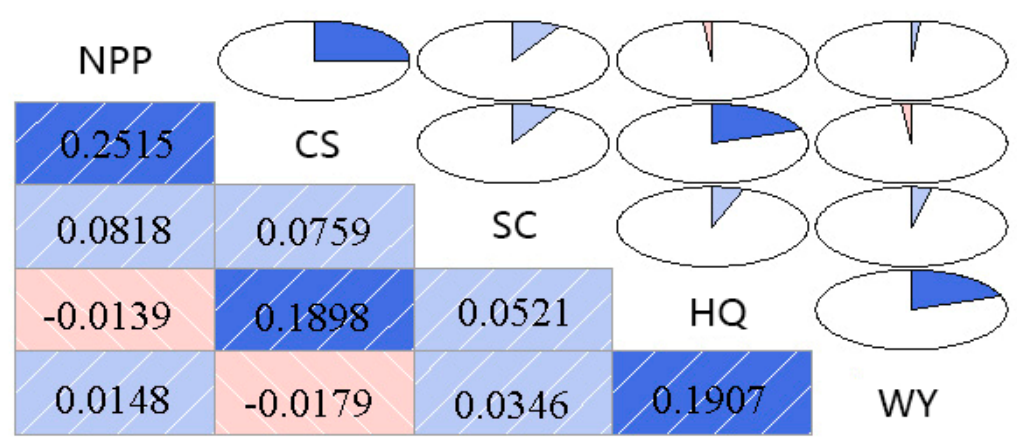

Figure 4. Corrgram of ES pairs in the Yellow River Basin (the values in the lower-left of each graph are the correlation coefficients of each ES pair in the whole Yellow River Basin).

In terms of space (Figure 5), WY and NPP in the basin are mainly synergistic. The synergy relationship is particularly prominent in the "Hetao Plain -Ningxia Plain -Lanzhou -Sanmenxia" area. The rainfall and vegetation coverage is low in the Hetao Plain, Ningxia Hui Autonomous Region, and Lanzhou. In this area, the WY and NPP are relatively low. From Shaanxi to Sanmenxia, there is abundant rainfall, high WY, and abundant water and heat conditions, which contributes to the increase of vegetation coverage. The NPP is relatively high. In the Bayan Har Mountains in the upper reaches of the Yellow River Basin and in Yan'an, Shaanxi and other places in the middle reaches of the Yellow River Basin, WY, and NPP are in a trade-off relationship. The upstream rainfall is rich and there are permanent glaciers and snowfields, where there is a high WY. At the same time, there are a large number of grasslands in this area, but the light is insufficient and the temperature is relatively low, so the NPP is low. While there are woodlands in Yan'an, Shanxi and other areas with sufficient sunlight, so the NPP is high. Woodlands can consume a lot of water resources, resulting in low WY in this area, and WY and NPP are in a trade-off relationship.

WY and SC are in a synergistic relationship. The Hetao Plain, Ningxia Plain, and Tianshui -Weinan in the middle reaches of the Yellow River Basin show a synergistic relationship. In the Hetao Plain and Ningxia Plain, there is low rainfall and low vegetation coverage, so WY and SC are low. In the Tianshui -Weinan area, there is abundant rainfall, high vegetation coverage, high water production capacity and soil conservation function, In Huangshui, Taohe and other places, vegetation coverage is high, the consumption of water leads to a decrease in WY, an increase in SC. Below Xiaolangdi, in the lower reaches of the Yellow River basin, most of the lands are for construction, and the WY is relatively high. On the contrary, because the area is densely populated, human activity is strong, and vegetation coverage is low, resulting in the decrease of SC, which makes a trade-off relationship between WY and SC. 

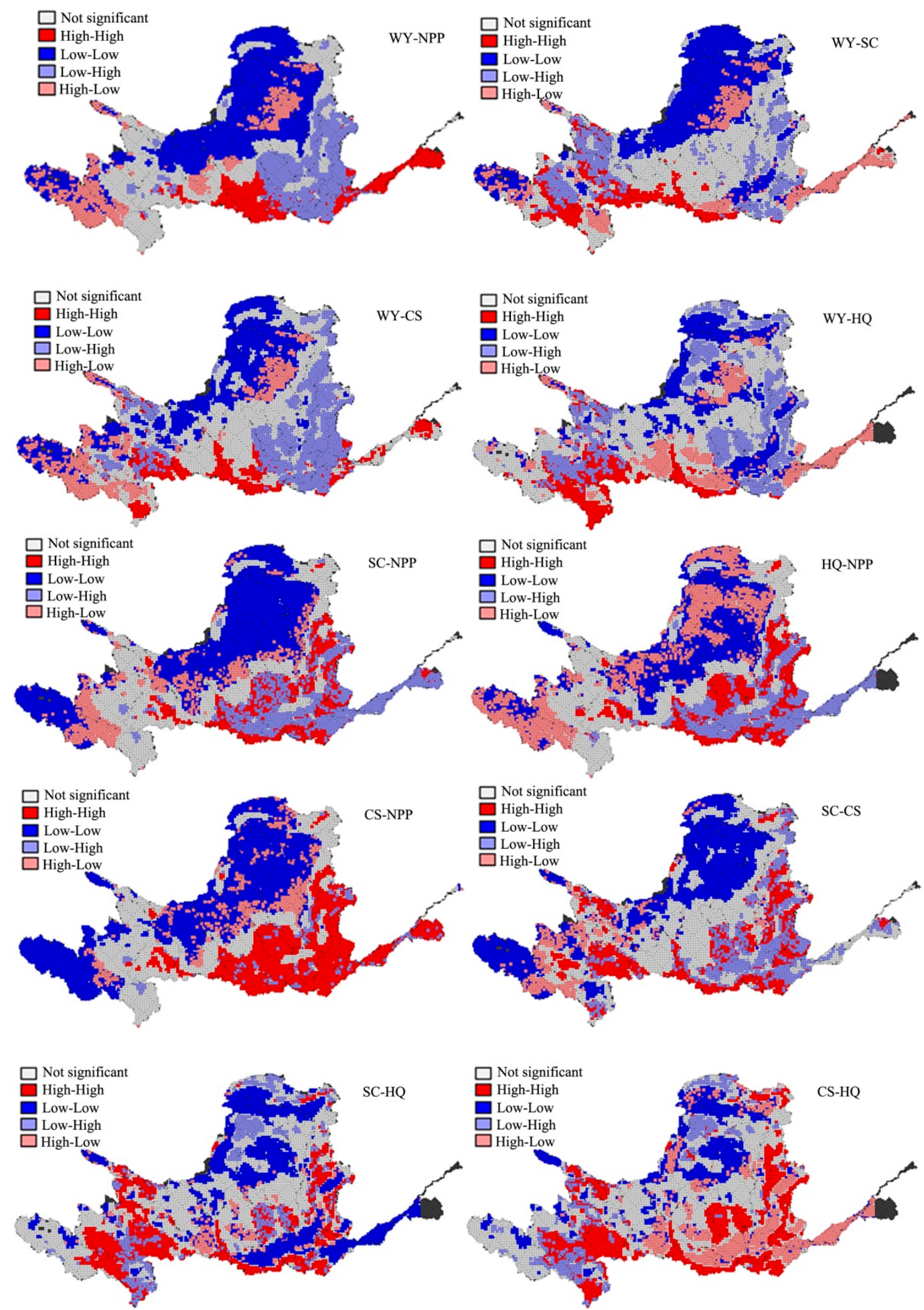

Figure 5. Schematic diagram of the coordination relationship space of the ESs of the Yellow River Basin.

WY and CS show a trade-off relationship throughout the entire region. The two are in a synergistic relationship in a small amount of areas of the upper reaches of the Yellow River Basin, the middle reaches of Inner Mongolia, and the Ningxia Hui Autonomous Region. The low precipitation and low vegetation coverage in this area result in low CS and WY. The trade-off relationship is mainly distributed in the upper and middle reaches. In the upper reaches of the Bayan Har Mountains and Zhaling Lake, low-coverage grasslands are mostly distributed, with relatively low CS and high WY. In the middle reaches, such 
as in Yan'an, Fenhe, and Shanxi, there are a large number of woodlands. The higher evapotranspiration and stronger interception capacity of woodland makes the WY of the land smaller. At the same time, the higher carbon density of woodland makes the higher CS in this area.

WY and HQ show a trade-off relationship. The trade-off relationship and the synergy relationship are interspersed and distributed throughout the basin, and there is no obvious dividing line. The upstream Maqu and the middle Qinling area have high vegetation coverage, strong rainfall, and low-intensity human interference. Therefore, the WY is high and the $\mathrm{Q}$ index of habitat quality is high. The Hetao Plain, Ningxia Plain, and Guanzhong Plain are located in arid and semi-arid areas with insufficient water and heat conditions, low vegetation coverage, poor water production capacity and habitats, and the two show a synergistic relationship. The distribution trade-off relationship is around the synergy relationship, which is mainly distributed in the Mu Us sandy land and below the Xiaolangdi Huayuankou in the lower reaches of the Yellow River. The land-use types are unused land and construction land, with less infiltration and large runoff, resulting in higher WY and vegetation. The coverage is low, the downstream population is dense, and human activiy is strong, destroying the connectivity of the habitat, resulting in poor HQ. To the west of Lanzhou, the west of Taihang Mountains, they are mostly distributed in high-coverage grassland and woodland due to the high vegetation coverage, which consumes and intercepts a large number of water resources, resulting in a decrease in WY. However, due to its high vegetation coverage, sparse population, and low destructive degree $\mathrm{HQ}$ is better. WY and HQ are in a trade-off relationship in the above regions.

NPP and SC are mainly synergistic in the whole region, mainly distributed in the central Qinghai -Tibet Plateau, the northern and southern areas of the Loess Plateau, and the lower reaches of the Yellow River Basin. Because of the strong regional dependence of NPP, it will increase with the increase of regional vegetation coverage. The change of coverage changes the resistance to rainfall erosion and indirectly affects the soil retention, so the two largely maintain consistent changes. NPP and CS are also mainly synergistic. From the angle of spatial distribution, the two are synergistic in most areas of the entire basin, and they are distributed throughout the upper and middle reaches of the Yellow River. Obviously, areas with higher vegetation coverage have higher NPP and CS. Compared with the Guanzhong Plain and Taihang Mountains, the upper Bayan Har Mountains, there is lower vegetation coverage in the northern and central parts of the Loess Plateau, so NPP and CS are lower.

NPP and HQ are in a synergistic relationship, most of which are distributed in the central Loess Plateau, Yan'an, and Shanxi. The central part of the Loess Plateau is dominated by the Mu Ussandy land. The land types are sandy and bare land where the vegetation coverage is low, so NPP and HQ are low. In Yan'an and Shanxi, there is high vegetation coverage, and good water and heat conditions, so NPP and HQ are high. However, in the Qinghai -Tibet Plateau and the Loess Plateau, the source area of the Yellow River, there is a trade-off between one and the other. Due to the low degree of human activities in these areas which are far away from threat sources such as cultivated land and construction land HQ is high. However, NPP is low in these areas due to insufficient light, low temperature, and photosynthesis.

SC and CS mainly show a synergistic relationship. They are obviously scattered in the middle reaches of the Loess Plateau and Qinling Mountains. The Loess Plateau is mainly concentrated in the Ningxia Hui Autonomous Region and the Mu Us Sandy Land. Due to its lower vegetation coverage and less rainfall, both SC and CS are low in this area. There are many woodlands in the Qinling Mountains, with high vegetation coverage and high carbon density, so SC and CS are high. CS and HQ are mainly in asynergistic relationship. In the Hetao Plain and the Mu Us Sandy Land, CS and HQ are low due to low vegetation coverage and poor climate conditions. In the Qinling Mountains, Yan'an and Taihang Mountains where woodland is the main land type, the high carbon density, good original vegetation, and low level of damage caused the CS and HQ to change simultaneously. 
However, in the lower reaches of the Yellow River and the Weihe Valley in the Guanzhong Plain, the land types are mainly woodland, cultivated land and construction land. The flat terrain, frequent human activities, and dense road crossings lead to habitat fragmentation and poor connectivity, resulting in poor HQ. So the two are in a trade-off relationship in these areas.

\subsection{ES Bundles}

The researchers identified the Yellow River Basin ES bundles by using the SOM model. First, they performed a principal component analysis of ESs. The results show that the first two principal components can explain $70 \%$ of the total variance of the variables, with WY and HQ having a higher positive load on the first principal component (PC1) and, NPP and CS having a higher positive load on the second component (PC2). The load difference of SC on the two principal components is relatively small. From the principal component analysis graph, it can be seen that NPP and CS are relatively closeand, HQ and WY are relatively close; NPP and WY tend to be perpendicular, and SC and other ecological services are at a certain distance. Therefore, it is recommended to divide the five ESs into three clusters based on the results of principal component analysis.

The SOM clustering algorithm has been widely used in the field of environmental science. This algorithm can effectively consider the topological relationship between the input data and is of great significance for the division of ES bundles [7]. The spatial distribution clustering of ESs is mainly divided based on the relative similarity of the various services provided by different geographic regions. Therefore, clustering can directly reflect the spatial differences in the supply level of specific ESs in different regions. According to the spatial distribution and correlation of the five ESs, the Yellow River Basin can be divided into three regions as shown in Figure 6: The results of the bundles are similar to the upper, middle, and lower basins of the Yellow River Basin, and bundles 1 and 2 arev basically bound by the transition bundles between the Loess Plateau and the Qinghai-Tibet Plateau. Based on the ecological function bundles, it obtains the ESs of each ecological function in the district and performs normalization processing by adopting the district statistics means, aiming to analyze each district within the ES structure, and then identifies the active ES function of each district (Figure 6). According to the result of the division:

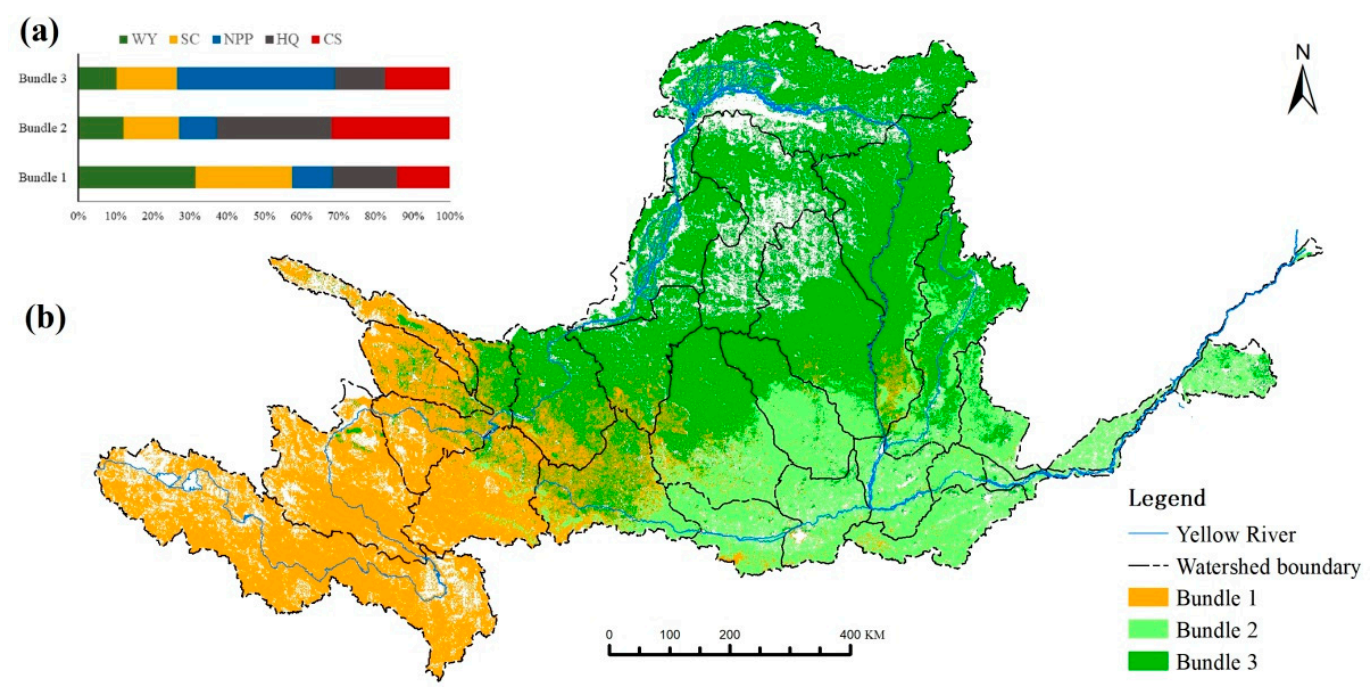

Figure 6. The spatial distributions of the three ES bundles in Yellow River Basin; (a) the proportion of the standardized value of each ES bundle; (b) the ES bundles map.

\subsubsection{Bundle 1: The Dominate Functional Area of WY and SC}

It mainly includes three-level river basins such as Maqu to the source of the river, Maqu to Longyang Gorge, Longyang Gorge to Lanzhou, Daxia River and Tao River, Weihe 
River and above Baoji Gorge, Huangshui River, and Datong River Basin. The regional area accounts for $39.35 \%$ of the total area of the Yellow River Basin. WY and SC are significantly higher than that in the other two regions. In this region, there is a plateau mountain climate, affected by the large-scale climate of the Qinghai-Tibet Plateau, with concentrated precipitation, many lakes, grasslands, and swamps, low water consumption and low evapotranspiration. At the same time, vegetation coverage is relatively high, so the conservation services of soil are strong, indicating that the core functions of ESs in this area are WY and SC.

\subsubsection{Bundle 2: The Dominate Functional Area of HQ and CS}

It mainly includes three-level river basins such as the Qingshui River and the Kushui River Basin, Xiaheyan to Shizuishan, Shizuishan to the north bank of Hekou Town, Shizuishan to the south bank of Hekou Town, internal flow area, the right bank above Wubao, and the right bank below Wubao. The regional areas account for 35.18\% of the total area of the Yellow River Basin. This area is an important functional area for habitat maintenance and carbon storage. There are many types of land use/cover, which mostly are grassland and woodland. However, bare land and sandy land are also distributed in the central area. Due to the large area and the distribution of vegetation types, having high carbon density such as woodland and grassland, the CS is higher. At the same time, as there is a lower degree of accessibility by human activities in these areas which are also far away from threat sources, such as cultivated land and construction land HQ is higher than that of in downstream areas. However, the WY service is low and evapotranspiration capacity is strong in the area. The largest annual evaporation in the region is in this area, which can exceed $2500 \mathrm{~mm}$ at most. The insufficient precipitation in the middle reaches leads to the lack (and uneven distribution) of water resources. In addition, the service function of NPP is enormously lower than that of other areas. Because this area is located in the hinterland of the inland, it forms a natural landscape with a dominant arid and semi-arid ecosystem. The vegetation structure is simple relatively and the productivity is low in this area, which is an extremely poor biomass area in the terrestrial ecosystem of the Yellow River Basin.

\subsubsection{Bundle 3: The Dominate Functional Area of NPP}

It distributes in the Fenhe River Basin, the Weihe River from Baoji to Xianyang, and below. The regional area accounts for $25.47 \%$ of the total area of the Yellow River Basin. Comparing with various ESs, it is found that the NPP service in this area has obvious advantages, so it is the dominant functional area of NPP service. The terrain is relatively flat in these areas, and the mainstream of the Yellow River and many tributaries pass through them. It is a temperate monsoon climate with sufficient water and heat conditions, which is beneficial to vegetation growth and restoration. The woodland coverage is higher in the Qinling Mountains, so the NPP is higher. However, other services are low in this area, especially HQ. Due to the concentrated distribution of arable land and construction land in this area, the habitat is fragmented, the connectivity is reduced, and the distance to the threat factor is relatively small, resulting in low HQ. The population below Xiaolangdi Huayuankou is dense, the land for economic construction is concentrated, the vegetation coverage is extremely low, and so, the SC is small.

\section{Discussion}

Reasonably regulating the time-space trade-offs between multiple services and clarifying their socio- economic- ecological environment driving mechanism is of great significance to the sustainable management of the ecosystem and the formulation of land use planning [44]. This paper systematically analyzes the spatial associations of the five important ESs in the Yellow River Basin and their social- ecological driving mechanisms. First, it analyzes the spatial distribution of the five ESs quantitatively; then compares and analyzes trade-off and synergy among ESs and their spatial distributions. 


\subsection{The Trade-Off and Synergy Relationship of ESs}

Identifying the interrelationships between ESs is essential for understanding services and guiding decision-making [45]. However, the interactions between ESs are not all linear. Therefore, the interaction between them can be understood only by evaluating multiple ESs [11]. (Howe et al., 2014). The spatial distribution patterns of the five ESs in the Yellow River Basin are related, and the results are similar to and different from related studies. Supply services and other services usually have a trade-off relationship, especially among agricultural production, water production services, and regulation services such as carbon fixation, pollutant retention, and soil conservation [46]. The results of this study show that there is a trade-off relationship between WY and CS, but the relationships among water production and SC, HQ, and NPP are synergistic. Bennett et al. believe that the nonlinear relationship between ESs is under the basis of the following two mechanisms: one is driven by common influencing factors; another is the interactions between multiple ESs [47]. Driven by common factors such as rainfall and terrain, there is a synergistic relationship between WY and SC. The increase of NPP can inhibit WY by increasing canopy interception [48]. HQ, SC, and CS are in a spatially synergistic relationship that is to say, a complete habitat with low interference can offer a superior environment for various organic substances, thereby promoting some adjustment service functions [49].

This conclusion affirms the support function of HQ, and HQ is in a trade-off relationship with NPP. There are high altitudes and low temperatures in the places with high $\mathrm{HQ}$, which are not conducive to the photosynthesis of vegetation. In downstream areas with high NPP, frequent human activities lead to lower habitat quality. There is a trade-off relationship between CS and NPP. Although both of these are carbon- related services and share a similar carbon cycle, CS represents the stock of carbon and NPP represents the rate of carbon sequestration. There is an opposite relationship between the two. This result is supported by the findings of Zhang et al. [50]. In the Yellow River Basin, there is a wide range of east- west and north- south spans. It is a transitional bundles between the east and the west in our country. The transition has an impact on the barrier and differentiation of the region, resulting in differences in topography, landforms, and climate, which will affect the ecosystem and will promote the difference in ES relationships. The Yellow River Basin spans the Qinghai- Tibet Plateau, the Inner Mongolia Plateau, the Loess Plateau, and the Huanghuaihai Plain from the west to the east. The height difference between the east and the west is huge, and the climate of different regions is obviously different. The Yellow River Basin is mainly in the southern temperate bundles, middle temperate bundles and plateau climate bundles. These differences make the vegetation, soil, animals and plants in the Yellow River Basin show significant latitude zonality differences, longitude differentiation, and natural rules, such as vertical zonality and slope differentiation, which promote the high complexity and diversity of ESs in the Yellow River Basin, and more importantly, promote the spatial heterogeneity.

\subsection{Factors Affecting the Spatial Distribution of ESs}

It performs statistical modeling on the social- ecological environmental factors of the five ESs in the Yellow River Basin in 2018 by, using the random forest regression model. The fitting degrees are all above 0.90, indicating that the model can well fit the spatial distribution differences of ESs. The relative weights of the eight environmental factors on the spatial distribution of the five ESs are shown in Figure 7, WY is affected by climatic factors more, especially precipitation, which is consistent with the results of previous studies [51]. WY is the result of comprehensive consideration of the balance of harvest (precipitation) and support (actual evapotranspiration) during the regional water cycle. Therefore, WY is not only greatly affected by rainfall, but also affected by the actual evapotranspiration in the region. The actual evapotranspiration is not only affected by weather factors (temperature, wind speed, relative humidity and sunshine hours, etc.), it is also affected directly by the land use/cover of the underlying surface. The land use impact on actual evapotranspiration is mainly through changing the underlying surface conditions, 
thereby affecting WY [52]. SC is mainly affected by rainfall, because precipitation is one of the leading factors that cause soil erosion. The increase in precipitation leads to intensified soil erosion, which leads to a decrease in soil conservation [53]. The results show that slope is also one of the important factors affecting SC, because there is less human disturbance, higher vegetation coverage, lower actual erosion, and larger soil conservation in the steep slope area [54]. In the plain area of the lower Yellow River, despite the heavy rainfall, flat terrain, and small vegetation coverage, the actual erosion amount is also large, so the SC is small, and other factors have no obvious impacts on the SC. Land use type is the most important factor affecting CS. From the perspective of the spatial distribution of CS, the upper reaches of the Yellow River Basin, Luohe River Basin, Fenhe River Basin and Qinling Mountains are the high-value areas of CS, which are mainly woodland and high-coverage grassland, with good vegetation conditions and strong carbon sequestration capacity. The low-value of CS areas are mainly distributed in the Loess Plateau, especially the Mu Us sandy area in the north of the Loess Plateau and the Badain Jaran Desert in the north of the Helan Mountain and in the west of the Yellow River, which is mainly sandy and other unused lands. At the same time, the influence of temperature on CS is more important than other factors. This conclusion is consistent with the results of Zhao et al. [55], because the vegetation is easier to recover in areas with high temperatures. The spatial distribution of HQ is absolutely affected by the types of land use. The HQ of the Yellow River Basin as a whole presents the spatial characteristics of high in the west and low in the east, mainly because the upstream is dominated by woodland and grassland, while the cultivated land is concentrated in the downstream area. This is consistent with the researches in other regions at home and abroad [56-58]. At the same time, natural features such as topography, climate, and NDVI are stable endogenous driving factors relatively, which determine the HQ spatial distribution, while social economic activities considered as manageable external driving factors often lead to the degradation of HQ [59]. The influence of NDVI on NPP is much higher than other factors. The spatial distribution of NPP and NDVI tends to be consistent. Due to the sensitivity of NDVI to ground vegetation chlorophyll changes and high temporal and spatial resolution, it can sensitively reflect the dynamic changes of NPP [60].
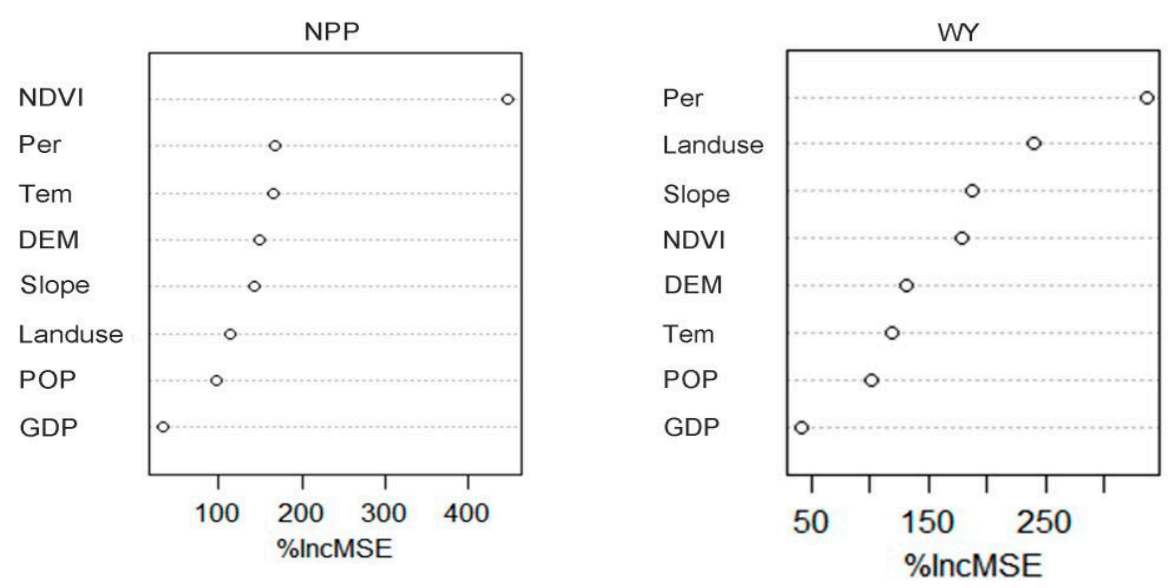

Figure 7. Cont. 

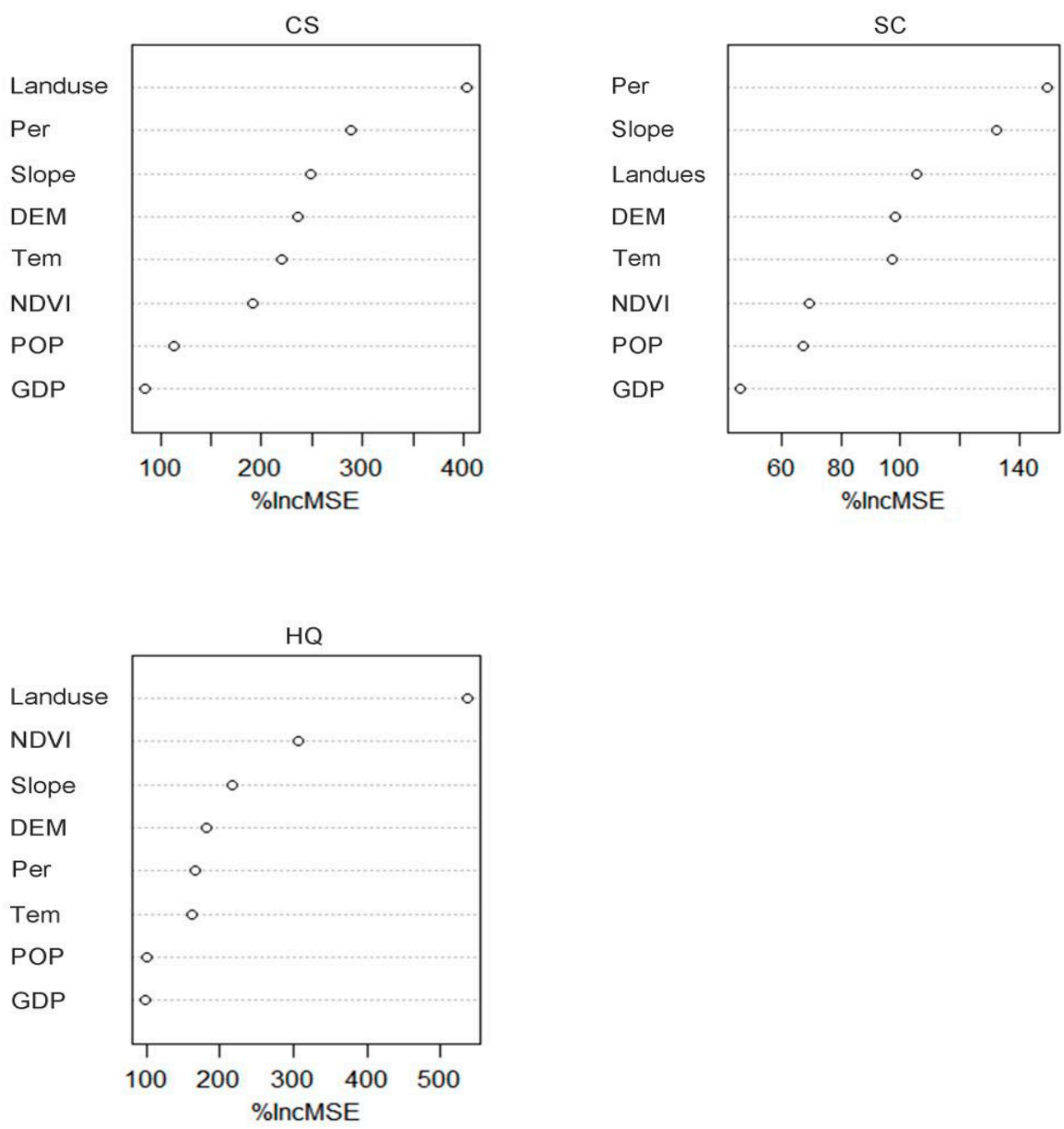

Figure 7. Impact factors and degree of impact of various ESs (Per: precipitation, Tem: temperature, POP: population density, GDP: gross domestic product).

\subsection{Land Use Management Implications}

Because the spatial heterogeneity of ESs determines different ES combinations, zoning can quickly identify areas with similar ecosystem clusters determined by similar social environment and other factors, so that policies can better formulate sustainable development strategies for different regions [61]. At the same time, ESs are affected by land-use ways and patterns, but most studies show that land-use types have the greatest impact on ESs [62]. Therefore, policy makers must understand how to construct land-use structures in a more reasonable way to promote regional sustainable development. Based on the bundles results of the Yellow River Basin, they put forward several suggestions for the future urbanization and land planning in different areas. In bundle 1, multiple ESs are superimposed here, with irreplaceable ecological functions. In future, it should be strictly managed as a key protected ecological function area, delineate the ecological protection red line, and strictly enforce the ecological access system. It is strictly forbidden to carry out various development activities that do not conform to the main function positioning in the area designated as the ecological protection red line. It is necessary to promote ecological protection, restoration and construction projects with grassland restoration as the main body, focusing on the Three Rivers, Qilian Mountains, and the upper reaches of the Yellow River in Gannan, so as to improve the authenticity and integrity of the ecosystem. In terms of implementation measures, the researchers adhere to the principle of ecological priority and organic integration of production and ecology. Grassland pastures such as Gannan Plateau should carry out ecological restoration, strictly implement grass-determining livestock, control livestock carrying capacity, fundamentally curb overloading and overgrazing, and remove part of the ecological system and carrying capacity to wild animals, and establish 
and improve a natural reserve system with national parks as the main body. Management measures such as the prohibition of grazing, rest grazing, reduction of grazing, and rotation of grazing should be taken to accelerate the restoration of degraded grasslands. Measures such as reseeding of native grass seeds and soil bioremediation should be adopted to accelerate the restoration and reconstruction of severely degraded grasslands, strengthen the protection of biodiversity, ensure the connectivity of habitat, and improve environmental carrying capacity and water conservation capacity. In bundle 2 , it encompasses the entire Loess Plateau. In this area, there is not only low rainfall and uneven distribution, but also heavy rainstorms, coupled with the loose structure of loess, so it is easy to form soil erosion. From 1950, our country began to adopt measures such as slope management, joint management of slope and gully, comprehensive consolidation of small watersheds, and returning farmland to forests and grasslands to control serious soil erosion problems in this area. In general, the currently implemented soil erosion control measures and projects in the Loess Plateau have achieved significant ecological benefits, and the overall regional ESs have developed in a healthy direction; however, the overall fragile characteristics of the Loess Plateau's ecological environment have not been changed. Therefore, people should not only consider reducing soil erosion and increasing the area of arable land for the management of this area, more importantly, they should also improve landscape varieties and the living environment, optimize the economic and industrial structure, and boost regional social and economic growth. Guided by the concept of landscape, forests, fields, lakes and grasses as a living community, people should practice the idea of "reinforcing the ditch and protecting the plateau in plateau areas, returning farmland to forests and grasses on slopes, blocking trenches for land preparation, and fixing sand and restoring shrubs and grasses in sandy areas". A comprehensive protection system for the plateau and ditch head with water systems and roads as the framework of fields, roads, forests, villages, shelter forests, etc. on the plateau and ditch should be formed to prevent the development of erosion ditch on the plateau. A ditch slope protection system that focuses on vegetation restoration, and combines engineering measures with forest, grass, and plant measures on the sloped surface is formed to reduce the water erosion of the ditch slope. The Saying Gully Scouring Forest has formed a gully protection system combining trench engineering and forest, grass and vegetation measures to prevent gravitational erosion such as collapses, landslides, and gully bank expansion. In bundle 3, it is a densely populated area with concentrated construction land. The disorderly and intensive urbanization process and agricultural development in this area are the main reasons for the loss of other important ESs. This is consistent with the results of other areas [63-65]. The expansion of cities has led to the reduction of the service functions of CS, HQ, and SC. The ESs in urban concentrated areas are mainly reflected in green infrastructure. Therefore, in urban core areas, it establishes the green belts to eliminate the side effects of increased impervious surfaces, taking into account the low contribution rate of unused land to ESs. Therefore, priority is given to unused land in site selection for new urbanization.

\section{Conclusions}

This study evaluated the five ESs of the Yellow River Basin in 2018, including WY, CS, SC, HQ, and NPP, and made a spatial expression with the three-level basin as a unit, and then quantitatively analyzed the trade-offs and synergies among the five ESs. It delineated the dominant ecological service function bundles of the Yellow River Basin based on the SOM method. The main conclusions are as follows:

The spatial distribution of the five ESs not only shows spatial heterogeneity, but also reflects certain regional laws. The upper reaches of the basin show higher ES, in particular, WY, SC and HQ are significantly higher than that of in the middle reaches and lower reaches of the Yellow River basin; however, ESs are generally lower in the middle reaches.

NPP has a synergistic relationship with CS, SC, and WY, and a trade-off relationship with HQ. CS has a synergistic relationship with SC and HQ, and a trade-off relationship with WY. The trade-off synergy relationship shows obvious spatial heterogeneity in space. 
The vegetation, soil, animals, and plants in the Yellow River Basin all show significant latitude zonality differences, longitude differentiation, and natural laws, such as vertical zonality and slope differentiation, which promotes the high complexity and diversity of ESs in the Yellow River Basin, more importantly, promotes the heterogeneity of space.

According to the spatial distribution and related relationships of the five ESs, the dominant ecological function services in the Yellow River Basin can be divided into three bundles. bundle 1 is the dominant function area for WY and SC services, bundle 2 is the dominant function area for HQ and CS services, and bundle 3 is the NPP service dominate function area.

This research makes a certain degree of assumptions about the linear relationship among various services based on correlation analysis. Studies have shown that there is a threshold for the relationship between ecosystem services. Therefore, the nonlinear relationship between ecosystem services should be strengthened, and multiple regression and constrained linear methods should be adopted in subsequent research.

Author Contributions: Conceptualization, J.Y., B.X. and D.Z.; identification, J.Y., W.T.; writingreview and editing, J.Y., B.X., W.T. and D.Z.; project administration, J.Y.; funding administration, D.Z.; All authors have read and agreed to the published version of the manuscript.

Funding: This research was was funded by the Scientific Research Start-up Funds for Openly Recruited Doctors (GAU-KYQD-2017-34) and National Key R\&D Program of China (No. 2016YFC0501902).

Institutional Review Board Statement: Not applicable.

Informed Consent Statement: Not applicable.

Data Availability Statement: The processed data required to reproduce these findings cannot be shared at this time as the data also forms part of an ongoing study.

Conflicts of Interest: The authors declare no conflict of interest.

\section{References}

1. Sharm, R.; Rimal, B.; Baral, H.; Nehren, U.; Paudyal, K.; Sharma, S.; Rijal, S.; Ranpal, S.; Acharya, R.P.; Alenazy, A.A.; et al. Impact of land cover change on ecosystem services in a tropical forested landscape. Resources 2019, 8, 18-31. [CrossRef]

2. MEA. Ecosystems and Human Well-Being: Current State and Trend: Synthesis; Island Press: Washington, DC, USA, 2005.

3. Fu, B.J.; Zhang, L.W. Land-use change and ecosystem services: Concepts, methods and progress. Prog. Geogr. 2014, 33, 441-446.

4. Acharya, R.P.; Maraseni, T.N.; Cockfield, G. An ecosystem services valuation research framework for policy integration in developing countries: A case study from Nepal. Sustainability 2020, 12, 8250-8265. [CrossRef]

5. Costanza, R.; De Groot, R.; Braat, L.; Kubiszewski, I.; Fioramonti, L.; Sutton, P.; Farber, S.; Grassog, M. Twenty years of ecosystem services: How far have we come and how far do we still need to go? Ecosyst. Serv. 2017, 28, 1-16. [CrossRef]

6. Wu, X.; Liu, S.; Zhao, S.; Hou, X.; Xu, J.; Dong, S.; Liu, G. Quantification and driving force analysis of ecosystem services supply, demand and balance in China. Sci. Total Environ. 2019, 652, 1375-1386. [CrossRef]

7. Cord, A.F.; Brauman, K.A.; Chaplin-Kramer, R.; Huth, A.; Ziv, G.; Seppelt, R. Priorities to advance monitoring of ecosystem services using earth observation. Trends Ecol. Evol. 2017, 32, 416-428. [CrossRef] [PubMed]

8. Lyu, R.F.; Zhang, J.M.; Xu, M.Q.; Li, J.J. Impacts of urbanization on ecosystem services and their temporal relations: A case study in Northern Ningxia, China. Land Use Policy 2018, 77, 163-173. [CrossRef]

9. Mouchet, M.A.; Lamarque, P.; Martín-López, B.; Crouzat, E.; Gos, P.; Byczek, C.; Lavorela, S. An interdisciplinary methodological guide for quantifying associations between ecosystem services. Glob. Environ. Chang. 2014, 28, 298-308. [CrossRef]

10. Deng, X.; Li, Z.; Gibson, J. A review on trade-off analysis of ecosystem services for sustainable land-use management. J. Geogr. Sci. 2016, 26, 953-968. [CrossRef]

11. Howe, C.; Suich, H.; Vira, B.; Mace, G.M. Creating win-wins from trade-offs? Ecosystem services for human well-being: A meta-analysis of ecosystem service trade-offs and synergies in the real world. Glob. Environ. Chang. 2014, 28, 263-275. [CrossRef]

12. Richards, D.R.; Friess, D.A. Characterizing coastal ecosystem service trade-offs with future urban development in a tropical city. Environ. Manag. 2017, 60, 961-973. [CrossRef]

13. Trodahl, M.I.; Jackson, B.M.; Deslippe, J.R.; Metherell, A.K. Investigating trade-offs between water quality and agricultural productivity using the Land Utilisation and Capability Indicator (LUCI)-A New Zealand application. Ecosyst. Serv. 2017, 26, 388-399. [CrossRef]

14. Tolessa, T.; Senbeta, F.; Kidane, M. The impact of land use/land cover change on ecosystem services in the central highlands of Ethiopia. Ecosyst. Serv. 2017, 23, 47-54. [CrossRef] 
15. Sun, Y.J.; Ren, Z.Y.; Hao, M.Y.; Duan, Y.F. Spatial and temporal changes in the synergy and trade-off between ecosystem services, and its influencing factors in Yanan, Loess Plateau. Acta Ecol. Sin. 2019, 39, 3443-3454.

16. Fu, B.J.; Yu, D.D. Trade-off analyses and synthetic integrated method of multiple ecosystem services. Resour. Sci. 2016, 38, 0001-0009.

17. Wang, B.; Zhao, J.; Hu, X.F. Analysis on trade-offs and synergistic relationships among multiple ecosystem services in the Shiyang River Basin. Acta Ecol. Sin. 2018, 38, 7582-7595.

18. Jiang, C.; Li, D.; Wang, D.; Zhang, L. Quantification and assessment of changes in ecosystem service in the Three-River Headwaters Region, China as a result of climate variability and land cover change. Ecol. Indic. 2016, 66, 199-211. [CrossRef]

19. Zoderer, B.M.; Tasser, E.; Erb, K.H.; Lupo Stanghellini, P.S.; Tappeiner, U. Identifying and mapping the tourists perception of cultural ecosystem services: A case study from an Alpine region. Land Use Policy 2016, 56, 251-261. [CrossRef]

20. Rositano, F.; Bert, F.E.; Piñeiro, G.; Ferraro, D.O. Identifying the factors that determine ecosystem services provision in Pampean agroecosystems (Argentina) using a data-mining approach. Environ. Dev. 2017, 25, 3-11. [CrossRef]

21. Cheng, G.D.; Li, X. Watershed science and its integrated research methods. Chin. Sci. Earth Sci. 2015, 45, 811-819.

22. Chen, Q.; Chen, Y.H.; Wang, M.J.; Jiang, W.G.; Hou, P.; Li, Y. Analysis on the change of net primary productivity of vegetation and the driving factors of climate in the Yellow River Basin from 2001 to 2010. Chin. J. Appl. Ecol. 2014, 25, $2811-2818$.

23. Piao, S.L.; Fang, J.Y.; Guo, Q.H. Application of CASA model to the estimation of Chinese terrestrial net primary produtiovity. Acta Phytoecol. Sin. 2001, 25, 603-608.

24. Zhu, W.Q.; Chen, Y.H.; Xu, D.; Li, J. Advances in terrestrial net primary productivity (NPP) estimation models. Chin. J. Ecol. 2005, 24, 296-300.

25. Zhu, W.Q.; Pan, Y.Z.; Long, Z.H.; Chen, Y.H.; Li, J.; Hu, H.B. Estimating net primary productivity of terrestrial vegetation based on GIS and RS: A case study in Inner Mongolia, China. Natl. Remote Sens. Bull. 2005, 3, 300-307.

26. Mu, S.J.; Li, J.L.; Zhou, W.; Yang, H.F.; Zhang, C.B.; Ju, W.M. Spatial-temporal distribution of net primary productivity and its relationship with climate factors in Inner Mongolia from 2001 to 2010. Acta Ecol. Sin. 2013, 33, 3752-3764.

27. Sharp, R.; Tallis, H.; Ricketts, T.; Guerry, A.; Wood, S.A.; Chaplin-Kramer, R.; Nelson, E. The Natural Capital Projet. In VEST 3.6.0 User's Guide; The Natural Capital Project, Stanford University: Stanford, CA, USA; University of Minnesota: Minneapolis, MN, USA; The Nature Conservancy: Arlington County, VA, USA; World Wildlife Fund: Gland, Switzerland, 2018.

28. Zhang, L.; Dawes, W.R.; Walker, G.R. Response of mean annual evapotranspiration to vegetation changes at catch-ment scale. Water Resour. Res. 2001, 37, 701-708. [CrossRef]

29. Yang, J.; Xie, B.P.; Zhang, D.G. Spatio-temporal variation of water yield and its response to precipitation and land use change in the Yellow River Basin based on InVEST model. Chin. J. Appl. Ecol. 2020, 31, 2731-2739.

30. Xie, X.L.; Sun, B.; Zhou, H.Z.; Li, Z.P.; Li, A.B. Estimation and spatial distribution of soil organic carbon density and storage in China. Acta Pedol. Sin. 2004, 41, 35-43.

31. Li, K.R.; Wang, S.Q.; Cao, M.K. Carbon storage of vegetation and soil in China. Sci. China 2002, 33, 72-80. [CrossRef]

32. Chen, L.J.; Liu, G.H.; Li, H.G. Remote sensing dynamic monitoring of net primary productivity of vegetation in China. J. Remote Sens. 2002, 6, 129-136.

33. Chuai, X.H.; Huang, X.J.; Lai, L.; Wang, W.J.; Peng, J.W.; Zhao, R.Q. Land use structure optimization based on carbon storage in several regional terrestrial ecosystems across China. Environ. Sci. Policy 2013, 25, 50-61. [CrossRef]

34. Liu, D.Q.; Gong, J.; Zhang, J.Q.; Ma, X.C. Spatiotemporal variation of soil conservation function and its influencing factors in Bailongjiang Watershed in Gansu Province. Res. Soil Water Conserv. 2018, 25, 94-103.

35. Bao, Y.B.; Liu, K.; Li, T.; Hu, S. Effects of land use change on habitat based on InVEST model-taking Yellow River wetland nature reserve in Shaanxi province as an example. Arid Zone Res. 2015, 32, 622-629.

36. Zhong, L.N.; Wang, J. Evaluation on effect of land consolidation on habitat quality based on InVEST model. Trans. Chin. Soc. Agric. Eng. 2017, 33, 250-255.

37. Liu, Y.; Bi, J.; Lü, J.S. Trade-off and synergy relationships of ecosystem services and the driving forces: A case study of the Taihu Basin, Jiangsu Province. Acta Ecol. Sin. 2019, 39, 7067-7078.

38. Zhang, X.R.; Zhou, J.; Li, G.N.; Chen, C.; Li, M.; Luo, J. Spatial pattern reconstruction of regional habitat quality based on the simulation of land use changes from 1975 to 2010. J. Geogr. Sci. 2020, 30, 601-620. [CrossRef]

39. Hou, Y.; Lu, Y.H.; Chen, W.P.; Fu, B.J. Temporal variation and spatial scale dependency of ecosystem service interactions: A case study on the central Loess Plateau of China. Landsc. Ecol. 2017, 32, 1201-1217. [CrossRef]

40. Hu, X.; Hong, W.; Qiu, R.; Hong, T.; Chen, C.; Wu, C. Geographic variations of ecosystem service intensity in Fuzhou City, China. Sci. Total Environ. 2015, 512-513, 215-226. [CrossRef]

41. Li, Y.J.; Zhang, L.W.; Qiu, J.X.; Yan, J.P.; Wan, L.W.; Wang, P.T.; Hu, N.; Cheng, W.; Fu, B. Spatially explicit quantification of the interactions among ecosystem services. Landsc. Ecol. 2017, 32, 1181-1199. [CrossRef]

42. Ying, H.; Zhang, H.Y.; Zhao, J.J.; Shan, Y.; Zhang, Z.X.; Guo, X.Y.; Rihana, W.; Denga, G. Effects of spring and summer extreme climate events on the autumn phenology of different vegetation types of Inner Mongolia, China, from 1982 to 2015. Ecol. Indic. 2020, 111, 105974. [CrossRef]

43. Kohonen, T.; Makisara, K. The Self-Organizing Feature Maps. Phys. Scr. 1989, 9, 168-172. [CrossRef]

44. Tammi, I.; Mustajärvi, K.; Rasinmäki, J. Integrating spatial valuation of ecosystem services into regional planning and development. Ecosyst. Serv. 2017, 26, 329-344. [CrossRef] 
45. Jiang, C.; Zhang, H.; Zhang, Z. Spatially explicit assessment of ecosystem services in China's Loess Plateau: Patterns, interactions, drivers, and implications. Glob. Planet. Chang. 2018, 161, 41-52. [CrossRef]

46. Zhou, Z.X.; Li, J.; Guo, Z.Z.; Li, T. Trade-offs between carbon, water, soil and food in Guanzhong-Tianshui economic region from remotely sensed data. Int. J. Appl. Earth Obs. Geoinf. 2017, 58, 145-156. [CrossRef]

47. Bennett, E.M.; Peterson, G.D.; Gordon, L.J. Understanding relationships among multiple ecosystem services. Ecol. Lett. 2009, 12, 1394-1404. [CrossRef]

48. Wang, Y.H.; Dai, E.F. Spatial-temporal changes in ecosystem services and the trade-off relationship in mountain regions: A case study of Hengduan Mountain region in Southwest China. J. Clean. Prod. 2020, 264, 121573. [CrossRef]

49. Peng, Y.X.; Wu, J.Z.; Luan, Z.P.; Feng, L. Evaluation of biodiversity in typical forest ecosystems in China: A review. For. Eng. 2013, $29,4-10$.

50. Zhang, P.; Zhang, Y.; Yang, G.; Zheng, Z.; Liu, Y.; Tan, Z. Carbon storage and sequestration of tree layer in subtropical evergreen broadleaf forests in Ailao Mountain of Yunnan. Chin. J. Ecol. 2010, 29, 1047-1053.

51. Yang, D.; Liu, W.; Tang, L.Y.; Chen, L.; Li, X.Z.; Xu, X.L. Estimation of water provision services for monsoon catchments of South China: Applicability of the InVEST model. Landsc. Urban Plan. 2019, 182, 133-143. [CrossRef]

52. Lang, Y.Q.; Song, W.; Deng, X.Z. Projected land use changes impacts on water yields in the karst mountain areas of China. Phys. Chem. Earth 2018, 104, 66-75. [CrossRef]

53. Liu, C.Y.; Zhu, K.W.; Liu, J.P. Evolution and prediction of land cover and biodiversity function in Chongqing section of Three Gorges Reservoir Area. Trans. Chin. Soc. Agric. Eng. 2017, 33, 258-267.

54. El, K.H.; Zhang, H.; Zhang, P.C.; Mosandl, R. Soil erosion and surface runoff on different vegetation covers and slope gradients: A field experiment in Southern Shaanxi Province, China. Catena 2013, 105, 1-10.

55. Zhao, M.M.; He, Z.B.; Du, J.; Chen, L.F.; Lin, P.F.; Fang, S. Assessing the effects of ecological engineering on carbon storage by linking the CA-Markov and InVEST models. Ecol. Indic. 2018, 98, 29-38. [CrossRef]

56. Ma, L.B.; Bo, J.; Li, X.Y.; Fang, F.; Cheng, W.J. Identifying key landscape pattern indices influencing the ecological security of inland river basin: The middle and lower reaches of Shule River Basin as an example. Sci. Total Environ. 2019, 674, 424-438. [CrossRef] [PubMed]

57. Brumm, K.J.; Jonas, J.L.; Prichard, C.G.; Watson, N.M.; Pangle, K.L. Land cover influences on juvenile Rainbow Trout diet composition and condition in Lake Michigan tributaries. Ecol. Freshw. Fish. 2019, 28, 11-19. [CrossRef]

58. Yang, W.; Jin, Y.; Sun, T.; Yang, Z.; Cai, Y.; Yi, Y. Trade-offs among ecosystem services in coastal wetlands under the effects of reclamation activities. Ecol. Indic. 2017, 92, 354-366. [CrossRef]

59. Yan, S.J.; Wang, X.; Cai, Y.P.; Li, C.H.; Yan, R.; Cui, G.N.; Yang, Z.F. An integrated investigation of spatiotemporal habitat quality dynamics and driving forces in the upper basin of miyun reservoir North China. Sustainability 2018, 10, 4625-4641. [CrossRef]

60. Jiang, R.Z.; Li, X.Q.; Zhu, Y.A.; Zhang, Z.G. Spatial-temporal variation of NPP and NDVI correlation in wetland of Yellow River Delta based on MODIS data. Acta Ecol. Sin. 2011, 31, 6708-6716.

61. Hamann, M.; Biggs, R.; Reyers, B. Mapping social-ecological systems: Identifying 'green-loop' and 'red-loop' dynamics based on characteristic bundles of ecosystem service use. Glob. Environ. Chang. 2015, 34, 218-226. [CrossRef]

62. Paterson, A.; Bryan, B.A. Food-carbon trade-offs between agriculture and reforestation land uses under alternate market-based policies. Ecol. Soc. 2012, 17, 21. [CrossRef]

63. Cumming, G.S.; Buerkert, A.; Hoffffmann, E.M.; Schlecht, E.; von Cramon-Taubadel, S.; Tscharntke, T. Implications of agricultural transitions and urbanization for ecosystem services. Nature 2014, 515, 50-57. [CrossRef] [PubMed]

64. Seto, K.C.; Gneralp, B.; Hutyra, L.R. Global forecasts of urban expansion to 2030 and direct impacts on biodiversity and carbon pools. Proc. Natl. Acad. Sci. USA 2012, 109, 16083-16088. [CrossRef] [PubMed]

65. Foley, J.A.; Ramankutty, N.; Brauman, K.A.; Cassidy, E.S.; Gerber, J.S.; Johnston, M.; Mueller, N.D.; O'Connell, C.; Ray, D.K.; West, P.C.; et al. Solutions for a cultivated planet. Nature 2011, 478, 337-342. [CrossRef] [PubMed] 